\title{
Incremental interpretation and discourse complexity
}

Jana Häussler and Markus Bader

Linguistics Department, University of Konstanz, Germany

https://doi.org/10.36505/ExLing-2006/01/0031/000031

\begin{abstract}
We will present two self-paced reading studies that provide new evidence on the incrementality of semantic interpretation, in particular with regard to the notion of discourse complexity as introduced by Gibson's distance-based dependency locality theory (DLT; cf. Gibson, 1998, 2000). More specifically, we will focus on the con-tribution of referential processing on sentence complexity. The experiments com-pared the processing of simple definite DPs like der Lehrer ('the teacher') and com-plex DPs containing a possessive NP like Peters Lehrer ('Peter's teacher'). While simple DPs introduce only a single discourse referent, complex DPs introduce two discourse referents and some relation between them. This additional processing ef-fort is reflected by increased reading times.
\end{abstract}

\section{Introduction}

In prior work (Bader and Häussler 2005) we investigated simple and complex DPs in experiments focussing on the processing of number ambiguous nouns in German. A number ambiguous noun like Lehrer is usually disambiguated by a determiner (der Lehrer 'the teacher' vs. die Lehrer 'the teachers'), but remains ambiguous when specified by a possessive proper name (Peters Lehrer 'Peter's teacher(s)'). We found that number ambiguous nouns cause garden-path effects on the clause-final disambiguating verb. Reading times on the verb correlate substantially with number preferences determined by a corpus analysis. The more often a noun occurs in the singular, the more often it is analyzed as a singular noun during first-pass parsing, leading to difficulties when encountering a verb specified for plural.

Furthermore, reading times at the noun were longer in ambiguous DPs than in unambiguous DPs. As an alternative or in addition to ambiguity, the increased reading times might be attributed to complexity. While unambiguous DPs intro-duce only a single discourse referent, ambiguous (= possessive) DPs introduce two discourse referents and some relation between them. This might cause addi-tional processing effort which is reflected in reading times.

Since complexity and ambiguity were confounded in these experiments we conducted two further experiments separating both factors by using two types of unambiguous material. Both experiments used a word-by-word noncumulative self-paced reading procedure.

ExLing 2006: Proceedings of 1st Tutorial and Research Workshop on Experimental Linguistics, 28-30 August 2006, Athens, Greece 


\section{Experiment 1}

Experiment 1 compares ambiguous nouns within a simple DP introduced by a determiner (der eine Lehrer 'the one teacher' and die beiden Lehrer 'the two teachers') and ambiguous nouns within a complex DP introduced by a possessive proper noun (Peters Lehrer 'Peters teacher(s)'). In contrast to the experiments reported above, the disambiguating verb precedes the ambiguous noun. A full set of examples is shown in (1).

(1) a. Zum Glück war Peters Teilhaber mit der Klausel ebenfalls einverstanden. to fortune was P.'s associate with the clause also agreeable 'Fortunately, Peter's associate also agreed with the clause.'

b. Zum Glück war der eine Teilhaber mit der Klausel ebenfalls einverstanden. to fortune was the one associate with the clause also agreeable 'Fortunately, the one associate also agreed with the clause.'

c. Zum Glück waren Peters Teilhaber mit der Klausel ebenfalls einverstanden. to fortune were P.'s associates with the clause also agreeable 'Fortunately, Peter's associates also agreed with the clause.'

d. Zum Glück waren die beiden Teilhaber mit der Klausel ebenfalls to fortune were the both associates with the clause also einverstanden. agreeable 'Fortunately, the two associates also agreed with the clause.'

Reading times on the ambiguous noun and thereafter in sentences like (1a) and (1c) were substantially longer than reading times on the noun in sentences like (1b) and (1d). Again, the increase already starts at the possessor (cf. Figure 1).

Since the verb precedes and therefore disambiguates the number ambiguous DP, we attribute these increased reading times to complexity instead of ambiguity.

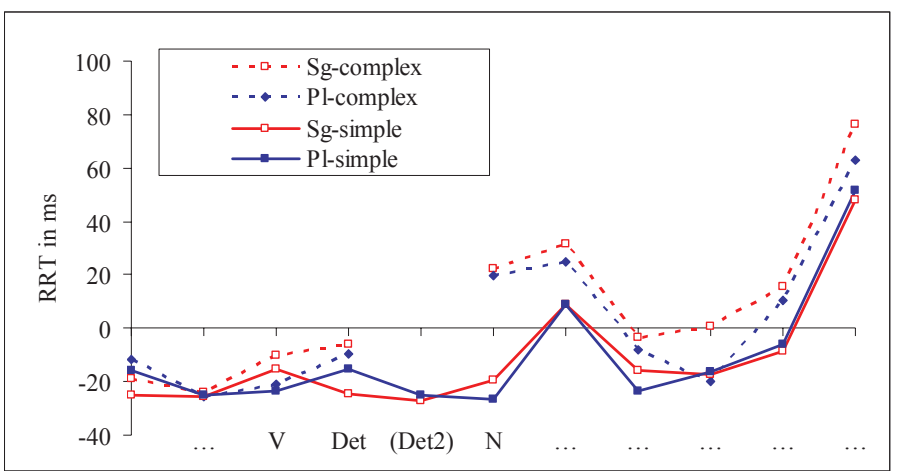

Figure 1. Residual Reading Times in Experiment 1. 


\section{Experiment 2}

Experiment 2 compares complex and simple DPs with either ambiguous masculine nouns as in the experiments before or unambiguous feminine counterparts. The resulting DP is the subject of an embedded verb-final clause. A set with unambiguous nouns is given in (2) Ambiguous DPs contained the corresponding masculine noun Teilhaber ('associate').

(2) Es hat sich jetzt herausgestellt, ... ('It turned out now')

a. dass Peters Teilhaberin mit der Klausel ebenfalls einverstanden war that P.'s associate (fem.) with the clause also agreeable was 'that Peter's associate also agreed with the clause'

b. dass die eine Teilhaberin mit der Klausel ebenfalls einverstanden war that the one associate (fem.) with the clause also agreeable was 'that the one associate also agreed with the clause'

c. dass Peters Teilhaberinnen mit der Klausel ebenfalls einverstanden waren that P.'s associates (fem.) with the clause also agreeable were 'that Peter's associates also agreed with the clause'

d. dass die beiden Teilhaberinnen mit der Klausel ebenfalls einverstanden waren that the both associates (fem.) with the clause also agreeable were 'that the two associates also agreed with the clause'

On the noun and thereafter, reading times for complex DPs were longer than for simple DPs, for both the ambiguous masculine nouns and the unambiguous feminine nouns. Since feminine DPs show the same specifier effect as masculine DPs, the increased reading times cannot be attributed to ambiguity but must rather reflect complexity differences between simple DPs and complex DPs. This supports the DLT's claim that introducing new discourse referents consumes processing resources and thereby slowes down processing. Interpreting Peter's associate requires the integration of two new discourse referents and establishing a dependency between them whereas interpreting the one associate requires the integration of only one new discourse referent.

In addition we found a main effect of gender and an interaction of number and gender. Reading feminine nouns took longer than reading masculine nouns. Furthermore, reading a feminine plural noun took longer than reading a feminine singular noun. For masculine nouns no such number effect was observed. This is probably a frequency effect: the corpus frequency for the experimental masculine nouns is about 7 times higher than for feminine singular nouns and 14 times higher than for feminine plural nouns. 

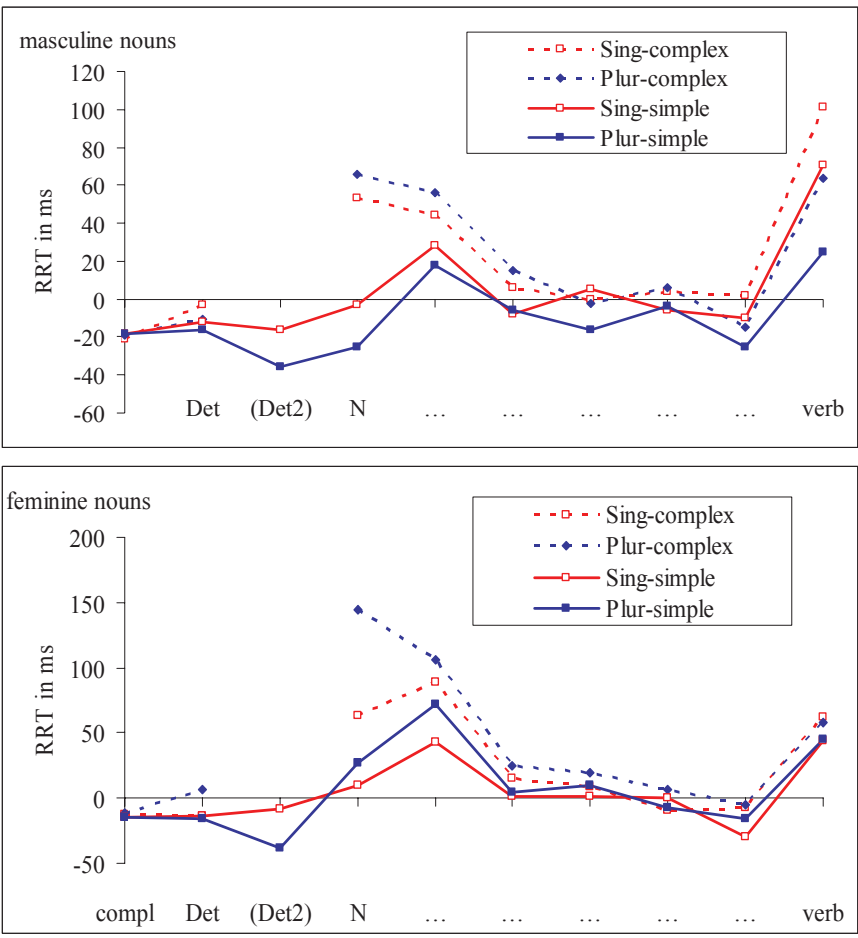

Figure 2. Residual Reading Times in Experiment 2

\section{Summary and Conclusions}

In sum, our results support the notion that discourse processing modulates on-line sentence complexity. Finding increased reading times immediately on the noun shows that syntactic structures are rapidly interpreted.

\section{References}

Bader, M. and Häussler, J. 2005. World-Knowledge and Frequency in Resolving Number Ambiguities. Presented at the 11th Annual Conference on Architecture and Mechanisms for Language Processing, Ghent, Belgium.

Gibson, E. 1998. Linguistic complexity: locality of syntactic dependencies. Cognition $68,1-75$

Gibson, E. 2000. The dependency locality theory: A distance-based theory of linguistic complexity. In Marantz, A., Miyashita, Y. and O’Neil, W. (eds.) 2000, Image, language, brain. Papers from the first Mind Articulation Project Symposium, 95-126. Cambridge, MIT Press.

Warren, T. and Gibson, E. 2002. The influence of referential processing on sentence complexity. Cognition 85, 79-112. 